\title{
The epidemiological survey for atovaquone resistant related gene of Babesia gibsoni in Japan
}

\author{
Aiko IGUCHI ${ }^{1) *}$, Takehisa SOMA ${ }^{2)}$, Hiroshi SUZUKI ${ }^{1)}$ and Xuenan XUAN ${ }^{1)}$ \\ 1) National Research Center for Protozoan Diseases, Obihiro University of Agriculture and Veterinary Medicine, Inada-cho, Obihiro, \\ Hokkaido 080-8555, Japan \\ 2) Veterinary Diagnostic Laboratory, Marupi: Lifetech Co., Ltd., 103 Fushio-cho, Ikeda, Osaka 563-0011, Japan
}

(Received 19 August 2015/Accepted 25 October 2015/Published online in J-STAGE 9 November 2015)

ABSTRACT. In 73 gDNA samples from Babesia gibsoni-infected dogs, the M121I variant population was measured by using allele-specific real-time PCR. Although the mechanism of atovaquone against $B$. gibsoni has not been clearly identified, it is reported that the mitochondria cytochrome $b$ gene of the atovaquone-resistant $B$. gibsoni had a single-nucleotide substitution at nt363 ( $\mathrm{G}$ to $\mathrm{T}$ ), which resulted in the substitution of methionine with isoleucine (M121I). In this study, 3/73 samples showed over 5\% M121I variant population. Although the M121I variant population is a low percentage, it runs the risk of spreading drug-resistant parasites. It is important to prevent the spread of drug-resistance, so we need to gather information about this at regular intervals.

KEY WORDS: allele-specific real-time PCR, Babesia gibsoni, drug resistance, M121I variant population

doi: 10.1292/jvms.15-0480; J. Vet. Med. Sci. 78(3): 489-491, 2016

Babesia gibsoni infects dogs' red blood cells and typically causes hemolytic anemia, which is often accompanied by fever, jaundice, hemoglobinuria and enlarged spleen $[1,2,4]$. A definitive strategy to eliminate $B$. gibsoni has not been established. Diminazene aceturate is used as a first-line drug for B. gibsoni infection in Japan. However, it often fails to eliminate the parasite from the affected dogs and causes severe adverse effects, such as pain at the injection site and nervous symptoms due to cerebral hemorrhage $[1,13]$. Some studies have reported the effectiveness of new combination therapies, such as clindamycin-metronidazole-doxycycline or doxycycline-enrofloxacin-metoronidazole, on experimentally infected dogs or in clinical cases; however, these therapies take a long time to show clinical effectiveness $[7,11]$. Atovaquone (ATV) is a well-tolerated, metabolically stable and effective agent with broad-spectrum anti-parasitic activity. ATV monotherapy was effective for acute canine $B$. gibsoni infection; however, it resulted in relapse and proliferation of ATV-resistant parasites with a single nucleotide polymorphism at nt363 in cytochrome $b$ (cyt $b$ ), which in turn caused the replacement of methionine with isoleucine (M121I) [8].

M121I appears to be responsible for the development of ATV resistance. M121I was detected in cyt $b$ of the ATVresistant $B$. gibsoni that showed lower sensitivity against ATV in vitro. On the other hand, development of ATV-resistant or gene polymorphisms on cyt $b$ was not confirmed by

*Correspondence to: Iguchi, A., National Research Center for Protozoan Diseases, Obihiro University of Agriculture and Veterinary Medicine, Inada-cho, Obihiro, Hokkaido 080-8555, Japan. e-mail: iguchi@obihiro.ac.jp

(C)2016 The Japanese Society of Veterinary Science

This is an open-access article distributed under the terms of the Creative Commons Attribution Non-Commercial No Derivatives (by-nc-nd) License $<$ http://creativecommons.org/licenses/by-nc-nd/4.0/>. exposing wild-type sibling clones to ATV [5]. Although the mechanism of ATV against B. gibsoni has not been clearly identified, the emergence of ATV resistance was suspected to be due to the selective multiplication of B. gibsoni M121I variants. However, the frequency and the ratio of the M121I variant population in the field are unknown. This study was conducted to detect the M121I variant population in the field. This is the first report about the M121I variant population in naturally infected dogs with $B$. gibsoni in Japan.

Seventy-three genomic DNA (gDNA) samples were collected from dogs naturally infected with $B$. gibsoni during 2011-2014. All samples were provided by a commercial laboratory (Marupi Lifetech Co., Ltd., Osaka, Japan). These samples were collected from clinically suspicious cases and confirmed to be positive for $B$. gibsoni infection by following $B$. gibsoni P18 gene PCR [3]. Table 1 shows the age, sex and breeds of dogs in these samples. There were no information about the dogs' histories and treatment including usage of ATV. They were collected from dogs mainly in areas west of Japan (Fukuoka, Oita, Yamaguchi, Hiroshima, Okayama, Hyogo, Ehime, Kochi, Kagawa, Osaka, Kyoto, Shiga, Mie, Wakayama and Aichi; only two samples were from the eastern part, Ibaraki and Hokkaido; Fig. 1).

An allele-specific SYBR green real-time PCR assay was performed to quantify the M121I variant population. To evaluate the M121I variant population, copy numbers were calculated for the wild-type allele (363G) and mutated allele $(363 \mathrm{~T})$ in the gDNA and were presented as the population ratio of $363 \mathrm{G}$ and $363 \mathrm{~T}$ alleles in the parasites [5]. gDNA from wild-type and ATV-resistant $B$. gibsoni in vitro cultures were used as negative and positive controls, respectively.

We measured the M121I variant population in 73 samples. The M121I variant population in 4 samples $(5.48 \%)$ were undetectable, and in 66 samples (99.41\%), they were under $1 \%$. In 3 samples $(4.11 \%$ ), they were over 1\%: 8.55\% (Jack Russell Terrier, male and 11 years, Yamaguchi), 14.04\% 
Table 1. The age, sex and breeds of dogs

\begin{tabular}{|c|c|c|c|c|c|}
\hline Age (years) & Number & Sex & Number & Breed & Number \\
\hline $0-1$ & 13 & Male & 39 & Mix & 15 \\
\hline $2-3$ & 6 & Female & 14 & Shih-tzu & 3 \\
\hline $4-5$ & 9 & Castration & 8 & Shetland & 2 \\
\hline $6-7$ & 13 & Antifertility & 8 & Shiba & 5 \\
\hline $8-9$ & 9 & Unknown & 4 & Toy poodle & 3 \\
\hline $10-11$ & 9 & Total & 73 & Tosa & 4 \\
\hline $12-13$ & 2 & & & Plott hound & 2 \\
\hline Unknown & 12 & & & Border collie & 3 \\
\hline \multirow[t]{7}{*}{ Total } & 73 & & & Pomeranian & 2 \\
\hline & & & & M. duchshund & 5 \\
\hline & & & & Yorkshire terrier & 3 \\
\hline & & & & Chihuahua & 3 \\
\hline & & & & Unknown & 12 \\
\hline & & & & Others* & 11 \\
\hline & & & & Total & 73 \\
\hline
\end{tabular}

*Others; Kangal dog, Welsh corgi, Golden retriever, Jack russell terrier, Dachshund, Bernese mountain dog, Pug, Papillon, French bulldog, M. schnauzer and M. pinscher.

(breed, sex and age unknown, Osaka), and 97.03\% (Mix, male and 13 years, Hiroshima).

In this study, we evaluated the M121I variant population in the field. ATV is a novel antiprotozoal compound that has broad-spectrum activity against human protozoan pathogens, including Plasmodium spp., Toxoplasma gondii and Babesia spp. After ATV treatment, B. gibsoni infection was relapsed, and the parasites had low sensitivity to second ATV treatment [8]. In our previous in vitro study, ATV-resistant $B$. gibsoni was successfully developed by exposing a wild-type uncloned B. gibsoni to $800 \mathrm{nM}$ ATV for 6 days. A SNP was detected in cyt $b$ of the ATV-resistant $B$. gibsoni, resulting in the amino acid substitution of M121I. The development of ATV resistance or gene polymorphisms on cyt $b$ was not confirmed by exposing 4 wild-type (WT) sibling clones to ATV. These results suggest that the M121I variant had selectively multiplied after 6 days of ATV exposure [5]. This indicates the importance of identifying the distribution of the M121I variant in the field. In this report, the M121I variant was detected in $4.2 \%$ of the population. In another report, M121I was detected in clinical in 3.3\% clinical cases (3/92 cases; Fukuoka, Kagoshima and Okinawa) [10]. B. gibsoni mostly occurs in western Japan and recently has spread to the eastern region. Although M121I was detected only in samples from the west, this might be because most of these samples were collected from western Japan. To our knowledge, there is no information about the usage of ATV in Japan. ATV might be used for more cases in the west, and this might explain the detection of M121I in samples from the west. Additional studies must include the collection of more samples from eastern Japan and the data regarding the usage of ATV. In addition, ATV-resistance related genes included M121I as well as M121V (nt361 A to G) in another study [9]. Allele-specific real-time PCR in this study could detect the population of M121I only; nt $363 \mathrm{G}$ changed to T. It is somewhat possible that another substitution at residue 121 may be responsible for the development of ATV resistance.
We found three cases that showed M121I variant population was over $1 \%(8.55 \%, 14.04 \%$ and $97.03 \%)$. In this study, we simply evaluated the M121I variant population by using gDNA from infected dogs. In addition, the dogs' medical histories were unknown. Therefore, we do not know whether the dogs infected with M121I B. gibsoni actually showed resistance against ATV treatment or not. In our previous study, the efficacy of Malarone ${ }^{\circledR}$, which contains ATV and proguanil (PG), against B. gibsoni infections was examined in 8 dogs. The M121I population before Malarone ${ }^{\circledR}$ treatment was under $0.1 \%$ in all dogs. After Malarone ${ }^{\circledR}$ treatment, the M121I population in 5/8 dogs changed to $15-96 \%$ [6]. It has not been clarified why there were differences in the M121I population after taking ATV. In this study, the M121I population also showed $8-97 \%$. Although the mechanisms for this change and the pharmacokinetics have not yet been unraveled, other factors in dog might affect the changing M121I population. It is also reported that three amino acid substitutions on cyt $b$ related to ATV resistance were detected in a clinical case in Hyogo Prefecture [12]. These substitutions included M121I, and this dog received ATV treatment. This indicates that receiving ATV may have implications on M121I populations. In a future study, we should check the relationship between the M121I variant population and ATV treatment before/after measuring the M121I variant population.

As a protozoan parasite, the most effective way to identify $B$. gibsoni infection is through blood sample testing. It is important to pay specific attention to the particular morphologies of Babesia in blood smears and to have a trained eye. The allele-specific real-time PCR used in this study was employed for the quantification of the M121I variant population among ATV-resistant B. gibsoni in our previous study [5]. This method is easy, quick and cost-effective. Allele-specific real-time PCR is a good method for defining the M121I variant population. To our knowledge, there is no information about the relationship between the M121I vari- 


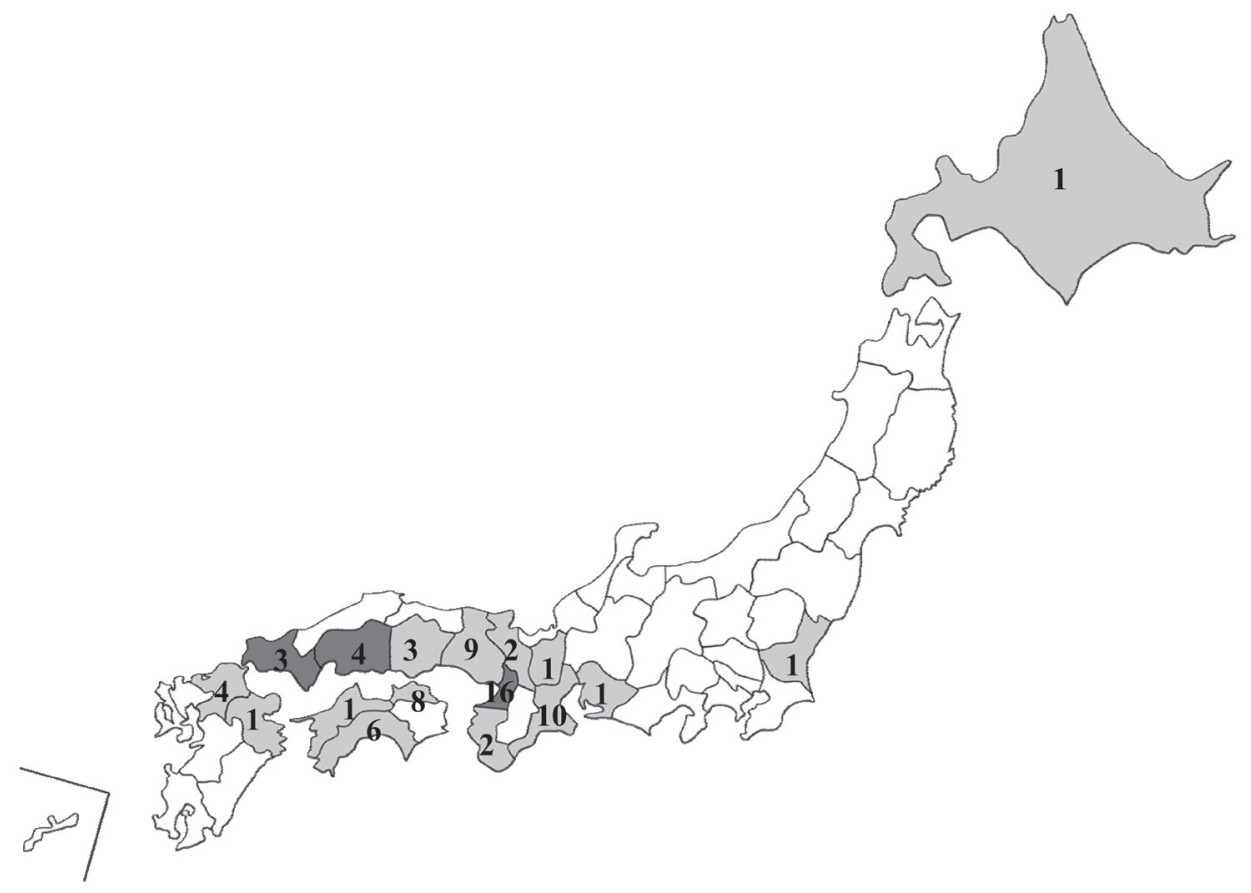

Fig. 1. Samples were collected from gray area. The number on the map showed sample numbers. Each 1 sample showed over 1\% M121I variant population in dark gray areas (Osaka, Hiroshima and Yamaguchi).

ant population and symptoms or treatment efficacies. Many samples and more information about dogs' medical histories and treatment are needed for a further study.

Although there were a low percentage of M121I variant population reported in this study, this population threatens to spread drug-resistant parasites. It is important to prevent the spread of drug resistance variants; therefore, we need to gather information about this at regular interval.

\section{REFERENCES}

1. Boozer, A. L. and Macintire, D. K. 2003. Canine babesiosis. Vet. Clin. North Am. Small Anim. Pract. 33: 885-904. [Medline] [CrossRef]

2. Farwell, G. E., Legrand, E. K. and Cobb, C. C. 1982. Clinical observations on Babesia gibsoni and Babesia canis infections in dogs. J. Am. Vet. Med. Assoc. 180: 507-511. [Medline]

3. Fukumoto, S., Xuan, X., Shigeno, S., Kimbita, E., Igarashi, I., Nagasawa, H., Fujisaki, K. and Mikami, T. 2001. Development of a polymerase chain reaction method for diagnosing Babesia gibsoni infection in dogs. J. Vet. Med. Sci. 63: 977-981. [Medline] [CrossRef]

4. Groves, M. G. and Dennis, G. L. 1972. Babesia gibsoni: field and laboratory studies of canine infections. Exp. Parasitol. 31: 153-159. [Medline] [CrossRef]

5. Iguchi, A., Matsuu, A., Ikadai, H., Talukder, H. and Hikasa, Y. 2012. Development of in vitro atovaquone-resistant Babesia gibsoni with a single-nucleotide polymorphism in cytb. Vet. Parasitol. 185: 145-150. [Medline] [CrossRef]

6. Iguchi, A., Matsuu, A., Fujii, Y., Ikadai, H. and Hikasa, Y. 2013. The in vitro interactions and in vivo efficacy of atovaquone and proguanil against Babesia gibsoni infection in dogs. Vet. Parasi- tol. 197: 527-533. [Medline] [CrossRef]

7. Lin, M. Y. and Huang, H. P. 2010. Use of doxycycline-enrofloxacin-metronidazole combination with/without diminazene diaceturate to treat naturally occuring canine babesiosis caused by Babesia gibsoni. Acta Vet. Scand. 52: 27. [Medline] [CrossRef]

8. Matsuu, A., Koshida, Y., Kawahara, M., Inoue, K., Ikadai, H., Hikasa, Y., Okano, S. and Higuchi, S. 2004. Efficacy of atovaquone against Babesia gibsoni in vivo and in vitro. Vet. Parasitol. 124: 9-18. [Medline] [CrossRef]

9. Sakuma, M., Setoguchi, A. and Endo, Y. 2009. Possible emergence of drug-resistant variants of Babesia gibsoni in clinical cases treated with atovequone and azithromycin. J. Vet. Intern. Med. 23: 493-498. [Medline] [CrossRef]

10. Sakuma, M., Fukuda, K., Takayama, K., Kobayashi, Y., Shimokawa, M. T., Setoguchi, A. and Endo, Y. 2012. Molecular epidemiological survey of the Babesia gibsoni cytochrome $b$ gene in western Japan. J. Vet. Med. Sci. 74: 1341-1344. [Medline] [CrossRef]

11. Suzuki, K., Wakabayashi, H., Takahashi, M., Fukushima, K., Yabuki, A. and Endo, Y. 2007. A possible treatment strategy and clinical factors to estimate the treatment response in Babesia gibsoni infection. J. Vet. Med. Sci. 69: 563-568. [Medline] [CrossRef]

12. Wickramasekara Rajapakshage, B. K., Yamasaki, M., Hwang, S., Sasaki, N., Murakami, M., Tamura, Y., Lim, S. Y., Nakamura, K., Ohta, H. and Takiguchi, M. 2012. Involvement of mitochondrial genes of Babesia gibsoni in resistance to diminazene aceturate. J. Vet. Med. Sci. 74: 1139-1148. [Medline] [CrossRef]

13. Wulansari, R., Wijaya, A., Ano, H., Horii, Y. and Makimura, S. 2003. Lymphocyte subsets and specific IgG antibody levels in clindamycin-treated and untreated dogs experimentally infected with Babesia gibsoni. J. Vet. Med. Sci. 65: 579-584. [Medline] [CrossRef] 